\title{
Effect of Cough Trick Method on Pain Intensity during Venipuncture Procedure among Hospitalized Children
}

\author{
Nahed K. Mohammed ${ }^{1}$, Eman S. Ahmed ${ }^{2}$, Mohammed A. Fathy ${ }^{3}$ \& Nora A. Zaki ${ }^{4}$ \\ 1- Assistant lecturer in Pediatric Nursing Department, Faculty of Nursing, Assuit University, Egypt. \\ 2-Professor of Pediatric Nursing ,Faculty of Nursing, Assuit University, Egypt. \\ 3- Professor of Pediatrics, Faculty of Medicine ,Assuit University, Egypt. \\ 3-Assistant Professor of Pediatric Nursing ,Faculty of Nursing ,Assuit University, Egypt.
}

\begin{abstract}
Background:- Painful medical procedures in childhood may have long-term negative effects on development and future tolerance of pain. Evidence recommends that a significant number of children get less than optimum management of procedure-related to pain. So this study aimed to assess effect of cough trick method on pain intensity during venipuncture procedure among hospitalized children. Quasi experimental research design was used in this study. Subjects included 60 hospitalized children recruited from emergency unit as well as medical and hematology units in Assuit University Children Hospital. They were selected randomly and divided into two groups: study \& control groups. Two tools were used for gathering necessary data which included, tool (1) A structured questionnaire sheet for personal and medical data, tool (II) Facial Pain Scale- Revised (FPS- R scale) that was used to assess pain intensity during venipuncture. Results showed that, there were a statistically significant difference in pain intensity in study group compared to control group $(1.00 \pm 2.15 \& 7.67 \pm 1.75)$. Conclusion cough trick was effective in reducing pain intensity during venipuncture. Therefore, it is recommended that the use of educational training program for nurses about using cough trick as non- pharmacological intervention to reduce pain among children.
\end{abstract}

\section{Keywords: Cough trick, Pain intensity, Venipuncture \& School age children}

\section{Introduction}

Pain perception in children is intricate and children frequently undergo medical procedures that are applied using a needle, such as venipuncture and immunization which considered the most common sources of pain for children causes considerable stress and anxiety for children and their parents (Anand \& Craig, 2014).

Venipuncture is one of the most widely used diagnostic and therapeutic procedures in children. Analgesia through venipuncture may be efficiently achieved with distracting techniques. The simple insertion of a needle has been exposed to be one of the most frightening and distressing medical procedures for hospitalized children. Additionally, fear of pain experienced due to medical procedures in childhood usually remains up to adulthood (McGrath \& Frager, 2017).

Numerous dissimilar modalities exist to reduce the pain associated with venipuncture in pediatric patients, with a variety of associated costs and efficiencies. When used suitably non-pharmacologic methods can be effective in dulling procedural pain. Non-pharmacologic methods used in children can be categorized in three main groups: supportive methods, cognitive/behavioral methods and physical methods (Humphery, et al., 2013).

The most broadly used non-pharmacological method for pain relief of children during painful medical procedures is the distraction method. Distraction is a nursing try focusing children's attention on any other stimulant so as to control and diminish pain better. The justification for the pain reducing effects of distraction is the suggestion that the brain has a restricted capacity of focusing attention on stimulation. If attention resources are diverted to focus on a distracting task, then little is left for attendance to painful stimulation. It has also been recommended that distraction varies nociceptive responses by triggering an internal pain suppressing system (Canbulat et al., 2015).

One novel alternative has the potential to reduce significantly the time, effort, and cost associated with addressing pediatric pain. This strategy, referred to as the "cough trick," needs that the children be provoked to give a single "warm-up" cough of moderate force, followed by a second cough that coincides with needle puncture. The cough trick resulted in clinically and statistically significant decreases in reported pain (Wallace \& Allen, 2015). 
The effectiveness of the procedure may come from distraction (concentrating on coughing on cue), competing sensory stimuli (noise and feeling of the cough), competing physiologic stimuli (eg, increased pressure in the subarachnoid space or increased blood pressure), or some combination of these factors. The strategy can be taught easily and requires no additional cost, equipment, or staff time. Therefore, it may prove to be a practical strategy even in busy pediatric clinics (Sahiner \& Bal, 2016).

Nurses acting a key role in identifying causes of pain, minimize exposure to painful medical procedures, proactively assessing and treating pain and have a responsibility to reduce pain and anxiety as much as possible while conserving children safety. Also, teaching the child and family about non pharmacologic methods of pain management, and reduction of pain by applying comfort measure. Nurses must be evaluating efficacy of treatment methods by paralleling pre and post treatments and watching for the side effect frequently (American Academy of pediatrics, 2016). It is also, important to assist the child and their parents when using the technique in order to make sure that they are using the technique correctly (Terri \& Susan, 2013).

\section{Significance of the study}

Recent years, many children have been exposed to diagnostic or therapeutic measures which create different levels of pain. WHO and several pediatric societies supporter improving the approach to pain in children in a medical environment. Venipuncture is one of the most painful invasive procedures that are frequently used in hospitalized children, because this method is the basis and introduction in the diagnosis and treatment of most children's diseases. Lack of pain relief during invasive procedures will have serious negative consequences especially when the pain is caused by needle insertion. Children's memory and recalling painful procedure will lead to severe psychological and physiological responses during the subsequent experiences of the child (Terri \& Susan, 2013). Coughing don't require any preparation and easy to be learnt among children to reduce pain.

\section{Aim of the Study}

The aim of this study was to determine the effect of cough trick method on pain intensity during venipuncture procedure among hospitalized children.

\section{Research hypothesis}

Children in the study group who use cough trick method experience have less pain intensity than those who were in control group during venipuncture procedure.

\section{Subjects \& Method \\ Research Design}

Quasi experimental research design was utilized in this study.

\section{Setting}

This study was conducted at emergency unit as well as medical and hematology units in Assiut University Children Hospital.

\section{Subjects}

A simple random sample was used in this study. The study was included 60 school age children, they were divided randomly into two groups, 30 children for each group (study who used the cough trick method and control group who received routine care). Complete randomization was carried out by drawing lots, the children with odd numbers belongs to the study group, and the ones with the even numbers belonged to the control group.

\section{Power analysis}

A power calculation estimated that in order to detect an effect size of 3.27 difference of pain score between means of two independent groups, with a pvalue $<0.05$ and $80 \%$ power, confidence level 0.95 , a sample size of 26 children for each group was needed. However, 30 children in each group were attempted in this research work to avoid nonresponse rate. This calculated using $\mathrm{G}$ Power 3.1 (Hsieh et al., 1998).

\section{Inclusion criteria included}

- School age children from 6-12 years old.

- The score of pain before venipuncture was zero..

- Children who didn't receive analgesic and hypnotic before intravenous insertion

\section{Exclusion criteria included}

- Children who had taken analgesic drugs within 24 hrs prior to blood sampling procedure.

- Children with fever, respiratory disorders, a medical history of fainting, or chronic diseases that causes pain.

\section{Tools of data collection}

Two tools were used to collect the required data for this study

Tool (1): A structured questionnaire sheet

It was developed by the researcher to collect the required data and it included the following two parts :Part (1): Personal data of studied children and their parents such as (age, residence, gender, birth order, care giver attendance, parent's education and occupation).

Part (2): Data related to previous and present venipuncture procedure of studied children such as, how much time had elapsed since the last blood sample was taken, venipuncture site, size of syringe, 
success of venipuncture, related problem in site of venipuncture, type of health problem, cause of hospital admission, previous hospitalization, and whether or not the child had a fear of needles.

Tool (II) Facial Pain Scale-Revised (FPS-R). It was developed by Nilsson et al., (2008), to assess pain in children aged 4-18years. It consisted of six facial expressions that evaluate the degree of pain, on a scale of $0-10$. Each face has score $(0,2,4,6,8,10$ ) from left to right. Its score ranged from zero (no pain) to ten (sever pain).

Scoring system of FPS-R scale:

$0=$ no pain

$2,4=$ mild pain

$6,8=$ moderate pain

$10=$ sever pain

Method of data collection

- An official permission was attained from the head of units, and also obtained from the manager of Assiut University Children Hospital.

- A pilot study was carried out on $10 \%$ (6) of the sample. The aim of the pilot study was to test the clarity and applicability of the tools and to estimate time needed to fulfill each sheet and the last form was established. No modification was done, so children who shared in the pilot study were included in the study.

- Validity of tool one was tested by measuring its Content Validity Index (CVI) by 5 experts in both pediatric nursing \& pediatrics, its CVI results was $95 \%$

- Reliability for tool one was estimated by Alpha Cronbach's test and its result was $\mathrm{R}=0.68$

- Reliability and validity of study tool two was assessed by ( Francesco et al., 2013) it was $(r=0 / 7, p<0 / 001)$.

\section{Field of the work}

This study was carried out through a period of seven months from the beginning of April (2018) to the end of October (2018).The researcher went to hospital two days per week from 8 am to 10 am to meet the children at emergency unit as well as medical and hematology units in the hospital after explaining the aim and nature of the study to parents of children and also obtain written parent consent for participation of their children in the study. The time needed for every child was 20 minutes (10 minutes for applying intervention and 10 minutes for filling questionnaire sheet from parent and child's sheet.

- Assessment of personal data of children and their parents and assessment of medical data was done by the researcher by using tool one (part1 and part2) for two groups.
- Assessment of pain level was done before and during a venipuncture.

\section{Procedure}

- Cough trick:- In the study group (I), the school age children were asked before the procedure to take a deep breath and cough actively during venipuncture. Children were video recorded for 2 minutes during venipuncture in order to identify the face of the child and compare the child's face with the aspect of FPS-R. The video recording were interpreted by the researcher and the total score of pain was calculated.

- The control group:- group (II), children in the control group were received the routine care only.

\section{Ethical Considerations}

Written informed consent was taken from parents of each child participating in the study and they are secured that data will be confidential and used only for the research purpose. The parents had the right to withdraw their children from the study at any time without any effect on the care provided for their children.

\section{Statistical analysis}

Date entry and data analysis were done using SPSS (Statistical Package for Social Science) version 19. Data were presented as number, percentage, mean and standard deviation. Chi-square test and Fisher exact test were used to compare qualitative variables. Independent samples t-test was used to compare quantitative variables in case of parametric data and Mann-Whitney test was used to compare between quantitative variables in case of non parametric data. $\mathrm{P}$-value was considered statistically significant when $\mathrm{P}<0.05$ 
Results

Table (1): Percentage distribution of studied children regarding to their personal data $(n=60)$.

\begin{tabular}{|c|c|c|c|c|c|}
\hline \multirow[t]{2}{*}{ Items } & \multicolumn{2}{|c|}{\begin{tabular}{|c} 
Study group (Cough trick Method) \\
$(\mathrm{n}=30)$
\end{tabular}} & \multicolumn{2}{|c|}{$\begin{array}{l}\text { Control group } \\
(\mathbf{n}=\mathbf{3 0})\end{array}$} & \multirow[t]{2}{*}{ P-value } \\
\hline & No. & $\%$ & No. & $\%$ & \\
\hline \multicolumn{5}{|l|}{ Gender } & \multirow{3}{*}{0.436} \\
\hline Male & 12 & 40.0 & 15 & 50.0 & \\
\hline Female & 18 & 60.0 & 15 & 50.0 & \\
\hline \multicolumn{5}{|l|}{ Age in years } & \multirow{4}{*}{0.832} \\
\hline $6-<8$ & 19 & 63.3 & 21 & 70.0 & \\
\hline $8-<10$ & 8 & 26.7 & 7 & 23.3 & \\
\hline $10-12$ & 3 & 10.0 & 2 & 6.7 & \\
\hline Mean \pm SD & \multicolumn{2}{|c|}{$7.33 \pm 1.42$} & \multicolumn{2}{|c|}{$7.23 \pm 1.41$} & 0.777 \\
\hline Range & \multicolumn{2}{|c|}{$7.0(6.0-11.0)$} & \multicolumn{2}{|c|}{$7.0(6.0-11.0)$} & \\
\hline \multicolumn{5}{|l|}{ Birth order } & \multirow{4}{*}{0.210} \\
\hline First & 8 & 26.7 & 14 & 46.7 & \\
\hline Second & 14 & 46.6 & 12 & 40.0 & \\
\hline Third & 8 & 26.7 & 4 & 13.3 & \\
\hline \multicolumn{5}{|c|}{ Parents' attendance during venipuncture } & \multirow{3}{*}{0.112} \\
\hline Mother & 26 & 86.7 & 30 & 100.0 & \\
\hline Father & 4 & 13.3 & 0 & 0.0 & \\
\hline
\end{tabular}

Table (2): percentage distribution of studied children regarding to their data related to previous and present venipuncture procedure $(n=60)$.

\begin{tabular}{|c|c|c|c|c|c|}
\hline \multirow[t]{2}{*}{ Items } & \multicolumn{2}{|c|}{$\begin{array}{c}\text { Study group } \\
\mathbf{n}=\mathbf{3 0}\end{array}$} & \multicolumn{2}{|c|}{$\begin{array}{c}\text { Control group } \\
n=30 \\
\end{array}$} & \multirow[t]{2}{*}{ P-value } \\
\hline & No. & $\%$ & No. & $\%$ & \\
\hline \multicolumn{5}{|c|}{ Time elapsed since the last blood sample/ months } & \multirow{5}{*}{0.294} \\
\hline $1<4$ & 6 & 20.0 & 11 & 36.7 & \\
\hline $4<8$ & 8 & 26.7 & 5 & 16.7 & \\
\hline $8<12$ & 8 & 26.6 & 4 & 13.3 & \\
\hline$\geq 12$ & 8 & 26.7 & 10 & 33.3 & \\
\hline \multicolumn{5}{|l|}{ Venipuncture site } & \multirow{6}{*}{0.228} \\
\hline Basilic vein & 18 & 60.0 & 11 & 36.7 & \\
\hline Cephalic vein & 5 & 16.7 & 10 & 33.3 & \\
\hline Dorsal metacarpal vein & 1 & 3.3 & 0 & 0.0 & \\
\hline Median cubital vein & 0 & 0.0 & 1 & 3.3 & \\
\hline Redial vein & 6 & 20.0 & 8 & 26.7 & \\
\hline \multicolumn{5}{|l|}{ Size of syringe: } & \multirow{3}{*}{0.488} \\
\hline $3 \mathrm{~cm}$ & 26 & 86.7 & 24 & 80.0 & \\
\hline $5 \mathrm{~cm}$ & 4 & 13.3 & 6 & 20.0 & \\
\hline \multicolumn{5}{|c|}{ Success of venipuncture: } & \multirow{3}{*}{0.781} \\
\hline $1^{\mathrm{st}}$ time & 20 & 66.7 & 21 & 70.0 & \\
\hline $2^{\text {nd }}$ time & 10 & 33.3 & 9 & 30.0 & \\
\hline \multicolumn{5}{|c|}{ Related problem in site of venipuncture: } & \multirow{3}{*}{0.117} \\
\hline Yes & 9 & 30.0 & 4 & 13.3 & \\
\hline No & 21 & $\mathbf{7 0 . 0}$ & 26 & 86.7 & \\
\hline Type of problem: & $n=9$ & & & & \multirow{4}{*}{0.575} \\
\hline Redness & 4 & 44.4 & 2 & $\mathbf{5 0 . 0}$ & \\
\hline Hematoma & 2 & 22.3 & 0 & 0.0 & \\
\hline Bleeding & 3 & 33.3 & 2 & 50.0 & \\
\hline
\end{tabular}


Table (2): Cont: percentage distribution of studied children regarding to their data related to previous and present venipuncture procedure $(\mathrm{n}=60)$.

\begin{tabular}{|c|c|c|c|c|c|}
\hline \multirow[t]{2}{*}{ Items } & \multicolumn{2}{|c|}{$\begin{array}{c}\text { Study group } \\
\mathbf{n}=\mathbf{3 0} \\
\end{array}$} & \multicolumn{2}{|c|}{$\begin{array}{c}\text { Control group } \\
n=30\end{array}$} & \multirow[t]{2}{*}{ P-value } \\
\hline & No. & $\%$ & No. & $\%$ & \\
\hline \multicolumn{5}{|c|}{ Cause of hospital admission: } & \multirow{4}{*}{0.733} \\
\hline Blood diseases & 12 & 40.0 & 15 & 50.0 & \\
\hline Endocrine diseases & 10 & 33.3 & 8 & 26.7 & \\
\hline Gastrointestinal diseases & 8 & 26.7 & 7 & 23.3 & \\
\hline \multicolumn{5}{|l|}{ Previous hospitalization: } & \multirow{3}{*}{0.058} \\
\hline Yes & 23 & 76.7 & 16 & 53.3 & \\
\hline No & 7 & 23.3 & 14 & 46.7 & \\
\hline \multicolumn{5}{|l|}{$\begin{array}{l}\text { Fear of needles due to } \\
\text { hospitalization: }\end{array}$} & \multirow{3}{*}{--} \\
\hline Yes & 23 & 100.0 & 16 & 100.0 & \\
\hline No & 0 & 0.0 & 0 & 0.0 & \\
\hline
\end{tabular}

Table (3): Difference between the level of studied children's pain for the study \& control groups during venipuncture according to their FPS-R scale $(n=60)$.

\begin{tabular}{|c|c|c|c|c|c|}
\hline \multirow{2}{*}{ Degree of pain } & \multicolumn{2}{|c|}{ Study group $(n=30)$} & \multicolumn{2}{|c|}{ Control group $(n=30)$} & \multirow{2}{*}{ P-value } \\
\hline & No. & $\%$ & No. & $\%$ & \\
\hline No pain (0 score) & 2 & 6.7 & 0 & 0.0 & \multirow{4}{*}{$0.000 *$} \\
\hline Mild (2,4 score) & 24 & 80.0 & 0 & 0.0 & \\
\hline Moderate (6,8 score) & 4 & 13.3 & 21 & 70.0 & \\
\hline Severe (10 score) & 0 & 0.0 & 9 & 30.0 & \\
\hline
\end{tabular}

Table (4):- Relationship between degree of facial pain scale revised and children's gender in study and control groups during venipuncture $(\mathrm{n}=60)$.

\begin{tabular}{|c|c|c|c|c|c|c|c|c|c|c|c|c|c|c|c|c|}
\hline \multirow{3}{*}{ Items } & \multicolumn{8}{|c|}{$\begin{array}{l}\text { Pain score (cough trick group) } \\
\qquad(n=30)\end{array}$} & \multicolumn{8}{|c|}{$\begin{array}{l}\text { Pain score (Control group) } \\
(\mathbf{n = 3 0 )}\end{array}$} \\
\hline & \multicolumn{2}{|c|}{ No pain } & \multicolumn{2}{|c|}{$\begin{array}{l}\text { Mild } \\
\text { pain }\end{array}$} & \multicolumn{2}{|c|}{$\begin{array}{l}\text { Moderate } \\
\text { Pain }\end{array}$} & \multicolumn{2}{|c|}{$\begin{array}{l}\text { Severe } \\
\text { Pain }\end{array}$} & \multicolumn{2}{|c|}{ No pain } & \multicolumn{2}{|c|}{$\begin{array}{l}\text { Mild } \\
\text { pain }\end{array}$} & \multicolumn{2}{|c|}{$\begin{array}{l}\text { Moderate } \\
\text { Pain }\end{array}$} & \multicolumn{2}{|c|}{$\begin{array}{l}\text { Severe } \\
\text { Pain }\end{array}$} \\
\hline & No & $\%$ & No & $\%$ & No & $\%$ & No & $\%$ & No & $\%$ & No & $\%$ & No & $\%$ & No & $\%$ \\
\hline \multicolumn{17}{|l|}{ Gender } \\
\hline Male & 11 & 91.7 & 0 & 0.0 & 1 & 8.3 & 0 & 0.0 & 0 & 0.0 & 0 & 0.0 & 11 & 73.3 & 4 & 26.7 \\
\hline Female & 13 & 72.2 & 2 & 11.1 & 3 & 16.7 & 0 & 0.0 & 0 & 0.0 & 0 & 0.0 & 10 & 66.7 & 5 & 33.3 \\
\hline P-value & \multicolumn{8}{|c|}{0.359} & \multicolumn{8}{|c|}{1.000} \\
\hline
\end{tabular}

Table (5): Relationship between degree of Facial Pain Scale- Revised and children's age in study and control groups during venipuncture $(n=60)$.

\begin{tabular}{|c|c|c|c|c|c|c|c|c|c|c|c|c|c|c|c|c|}
\hline \multirow{3}{*}{ Items } & \multicolumn{8}{|c|}{$\begin{array}{l}\text { Pain score (cough trick group) } \\
(n=30)\end{array}$} & \multicolumn{8}{|c|}{$\begin{array}{l}\text { Pain score (Control group) } \\
(\mathbf{n}=\mathbf{3 0})\end{array}$} \\
\hline & \multicolumn{2}{|c|}{ No pain } & \multicolumn{2}{|c|}{$\begin{array}{l}\text { Mild } \\
\text { pain }\end{array}$} & \multicolumn{2}{|c|}{$\begin{array}{l}\text { Moderate } \\
\text { Pain }\end{array}$} & \multicolumn{2}{|c|}{$\begin{array}{c}\text { Severe } \\
\text { Pain } \\
\end{array}$} & \multicolumn{2}{|c|}{ No pain } & \multicolumn{2}{|c|}{$\begin{array}{l}\text { Mild } \\
\text { pain }\end{array}$} & \multicolumn{2}{|c|}{$\begin{array}{c}\text { Moderate } \\
\text { Pain }\end{array}$} & \multicolumn{2}{|c|}{$\begin{array}{c}\text { Severe } \\
\text { Pain }\end{array}$} \\
\hline & No & $\%$ & No & $\%$ & No & $\%$ & No & $\%$ & No & $\%$ & No & $\%$ & No & $\%$ & No & $\%$ \\
\hline \multicolumn{17}{|c|}{ Age in years } \\
\hline $6-<8$ & 17 & 89.5 & 1 & 5.3 & 1 & 5.3 & 0 & 0.0 & 0 & 0.0 & 0 & 0.0 & 16 & 76.2 & 5 & 23.8 \\
\hline $8-<10$ & 6 & 75.0 & 1 & 12.5 & 1 & 12.5 & 0 & 0.0 & 0 & 0.0 & 0 & 0.0 & 4 & 57.1 & 3 & 42.9 \\
\hline $10-12$ & 1 & 3.3 & 0 & 0.0 & 2 & 66.7 & 0 & 0.0 & 0 & 0.0 & 0 & 0.0 & 1 & 50.0 & 1 & 50,0 \\
\hline P-value & \multicolumn{8}{|c|}{0.060} & \multicolumn{8}{|c|}{0.518} \\
\hline
\end{tabular}




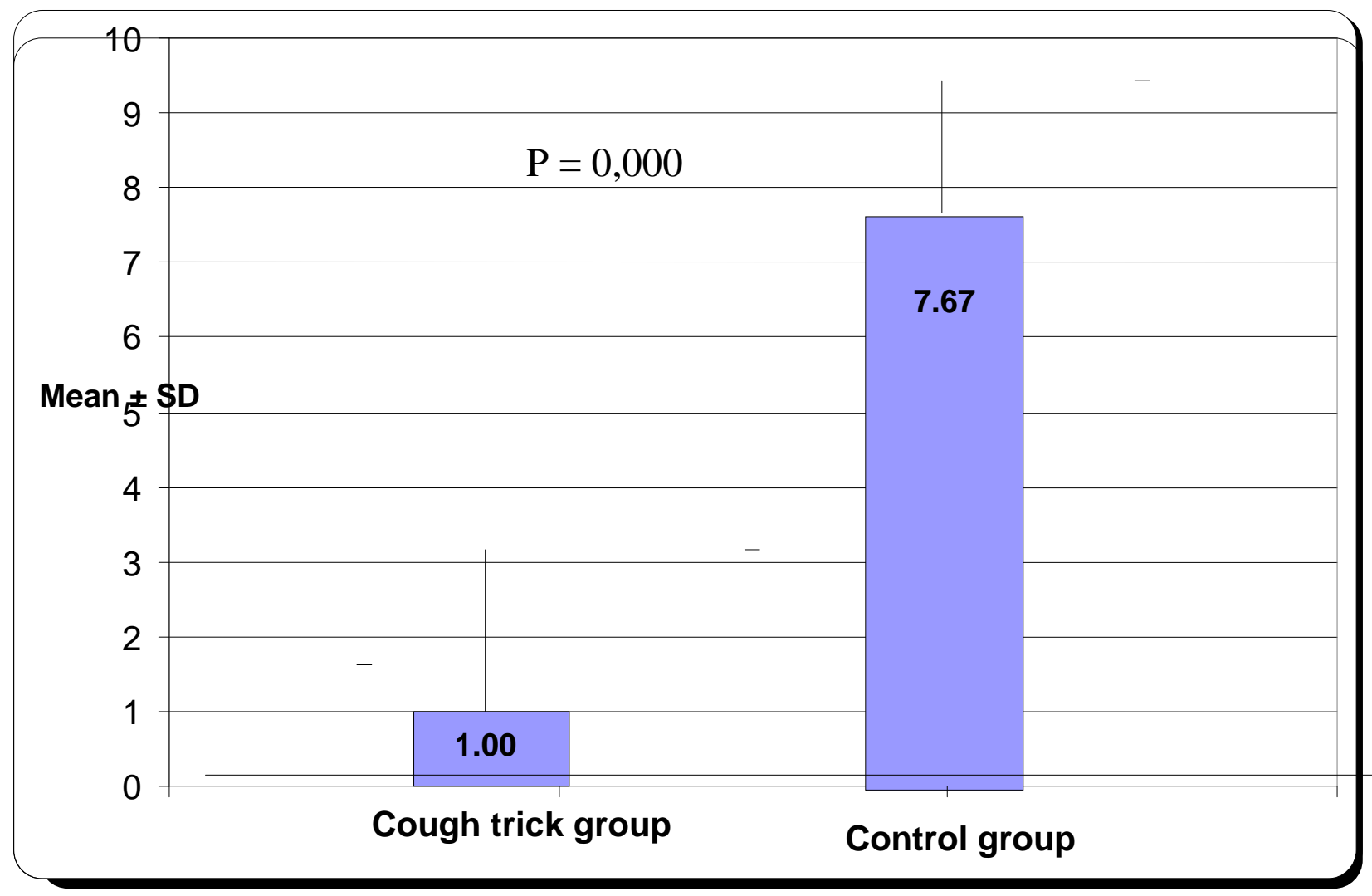

Figure (1): comparison between the two studied groups regarding the pain level

Table (1): Indicates percentage distribution of studied children regarding to their personal data. This finding revealed that more than half of studied children $(60.0 \%)$ in study group were female while only half $(50.0 \%)$ of control group were female and male. It was also found that more than half $(63.3 \%)$ $\&$ more than two thirds (70\%) of subject in study and control groups respectively were in age group $(6-<$ 8) years with p- value 0.777 .

Regarding children's birth order, it was observed that, less than half of children (46.7\%) in study group was the second child while only less than half $(46.7 \%)$ of them in the control group was first child. Also it was found that, mothers were accompanying the child $(86.7 \%$ \& $100.0 \%$ respectively) among the study and control groups. The two groups were matchable regarding all personal data, age, gender, birth order, residence and parents' attendance during venipuncture.

Table (2): Represents percentage distribution of studied children regarding to their data related to previous and present venipuncture procedure. It was found that, less than one quadrant $(20.0 \%) \&$ more than one third $(36.7 \%)$ in study \& control groups respectively were time elapsed since the last blood sample from $1<4$ months. Regarding venipuncture site, it was observed that more than half $(60.0 \%) \&$ more than one third $(36.7 \%)$ in study \& control groups respectively use basilic vein. Also the majority of them $(86.7 \% \& 80.0 \%$ respectively) used syringe $3 \mathrm{~cm}$ in two groups.

It was noted that $(66.7 \%$ \& $70.0 \%)$ in study and control groups respectively were success of venipuncture from $1^{\text {st }}$ time. Also it was found that half $(50 \%)$ of them were hospitalized because of blood diseases in control group while less than half $(40.0 \%)$ of them in study group were hospitalized because of gastrointestinal and blood diseases. It was observed also that, all of studied children in study and control groups fear of needle due to hospitalization.

Table (3): Demonstrates difference between the degree of studied children's pain for the study \& control groups during venipuncture. It was found that, $(80.0 \%)$ of studied children have mild pain in 
study group and $(70.0 \%)$ have moderate pain in control group with $(\mathrm{p}<0.000)$. While children in study group don't have any sever pain experience compared to one third $(30 \%)$ of them in control group.

Table (4): Illustrates relationship between studied children's gender and pain level. It was noticed that, there were no statistically significant relation between degree of pain and studied children gender between two groups.

Table (5): Illustrates relationship between studied children's age and pain level. It was noticed that there were no statistically significant relation between degree of pain and studied children's age between two groups.

Highly statistically significant differences was found between study and control groups during venipuncture according to their pain FPS-R scale with mean $\pm \mathrm{SD}(1.00 \pm 2.15,7.67 \pm 1.75)$ as clarified in figure (1).

\section{Discussion}

Pain is an unpleasant sensory and emotional feeling accompanying existing or impending tissue damage or referenced to such damage. venipuncture and venous cannulation are among the most invasive and painful procedures used to

treat hospitalized children and are possibly the most common cause of anxiety and distress. Distraction is a technique for pain relief and should be considered due to applicability, ease of use and ease of implementation and be used for other children who require frequent injections (Craig, 2016).

The results of the current study revealed that school age children who had not been directed in a painrelieving intervention experienced as moderate and severe pain during venipuncture as illustrated in table (3). This was consistent with Birsen multu, (2015), who conducted a similar study related to the effect of cough trick method on easing pain in children during the drawing of venous blood samples. Also the current study show that majority of studied children experienced mild pain during venipuncture in study group compared to none in control group. Our result also agree with that of Mohamed, (2017), who showed that cough trick was effective in reducing pain during venous blood drawing in children. This may be due to distraction with cough trick causes the child to attraction attention of the child away from pain stimuli during a medical procedure. Therefore, as a distraction method, cough trick might be useful for decreasing pain and anxiety during medical procedures.

The present study revealed that, highly statistically significance difference $\left(\mathrm{P}<0.000^{*}\right)$ was found between cough trick and control groups regarding degree of pain among children figure (1). This finding was in accordance with Dustin et al., (2014), who studied the "Cough trick:" a brief strategy to manage pediatric pain from immunization injections who found that cough trick is an effective for the reduction of pain and also in agreement with Betty et al., (2016), who studied the effectiveness of cough trick method in reducing immunization pain among children, demonstrated that cough trick was effectively and significantly in reducing pain in comparison with the control group.

Moreover, it is consistent with Karen, (2017), who conducted a study on the effect of distraction techniques on the pain of venipuncture in children. This may be due to cough trick increases intrathoracic pressure and stimulation to the autonomic nervous system, causing an increase in heart rate and blood pressure, a higher level of pressure in the subarachnoid space and baroreceptor activation. The increase in pressure in the subarachnoid space activates the segmental pain inhibiting pathways; thus, the increase in blood pressure and baroreceptor activation appears to be efficacious in reducing the perception of pain, and also this may be that using distraction has led to the child's obedience and relieving stress and pain caused by venipuncture.

According to the findings, there was no statistically significant difference between pain and gender in both groups during venipuncture Table (5). This result go on line with Ehsan et al., (2016), they studied the effect of distraction in the two groups of inflating the balloon and mother's armson on pain during venipuncture and they found that there were no statistically significant differences between the both sexes in the study and control groups. Also in contrary to other studies which reported differences in expressions of pain during invasive procedures between girls and boys, and also were contradict with Urden, et al., (2012), who noted that females' pain threshold is lower than male.

Regarding the relation between child's age and pain score level, there were no statistically significance differences between the pain score level and child's age in two groups during venipuncture Table (6). This result goes on line with Becky Hix, (2015) who found that no statistically significant difference was observed between age and severity of pain associated with venipuncture. In contrary to other studies which was reported by Karen, (2017) who noted that there were statistically significant differences between the pain level and child 'age. 


\section{Conclusion}

Based on the results of the present study, it could be concluded that cough trick method was effective in reducing pain during the procedure of drawing venous blood sample among children, there were no statistically significance differences were found between child's age, gender and pain score in both groups during venipuncture.

\section{Recommendations}

Based on the results of the current study, the following recommendations are suggested

1. Pediatric nurses should be encouraged to use the appropriate types of non-pharmacological intervention e.g., cough trick to reduce the intensity of pain among children during any invasive procedures.

2. Educational programs should be provided to increase knowledge and skills of health care professional particularly new nurses in applying non-pharmacological intervention such as cough trickto reduce pain intensity in children during any invasive procedures and also teach it to parents and encourage using with each venipuncture experience.

3. Cough trick is recommended to be used as standard care techniques for reduction of pain among children during the venipuncture also costeffective and have no complications and can be performed with an easy workout

4. Further research should be replicated and expanded to include a larger sample, focusing on outcomes with different children populations undergoing a variety of procedures in various settings.

\section{References}

1. American Academy of pediatrics (AAP), (2016): The assessment and management of acute pain in infant, children and adolescents, US National Library of Medicine, 108(3):793799.

2. Anand B., \& Craig P., (2014): New perspectives on the definition of pain, pain, Published by Elsevier Inc, 67(1): 3-6.

3. Becky H., (2015): Using distraction to reduce venipuncture pain and distress in school aged children, Master thesis of Health Science in the University of Canterbury: 575-582.

4. Betty D., Lebona G., Radhika M., \& Indira S., (2016): Assess effectiveness of cough trick method in reducing immunization pain among children, International Journal of Applied Research, 2(5): 625-630.
5. Birsen M., (2015): Effects of balloon inflation and cough trick methods on easing pain in children during the drawing of venous blood samples, Journal for Specialists in Pediatric Nursing, 2(1): 22-25.

6. Canbulat N., Keith D., Allen, Amy E., \& Lacroix A., (2015): Using of distraction methods on procedural pain management of pediatric patients. Journal of Health Science and Profession, 2(1): 372-378.

7. Craig K., (2016): The construct and definition of pain, edited by Tim Oberlander \& Frank J. Symons (Baltimore, USA: Paul H. Brookes Publishing Co:17-18.

8. Dustin P., Keith D., Amy E., \& Sheryl L., Pitner, (2014): The "Cough Trick:" A Brief strategy to manage pediatric pain from immunization injections, official journal of the American Academy of Pediatrics, 5(5): 101107.

9. Ehsan R., Mohammad S., \& Sanie N., (2016): The effect of distraction in the two groups of inflating the balloon and mother's armson on pain during venipuncture, International Journal of medical research, 5(1):331-335.

10. Francesco A., Jennifer, Z., Jennifer, A., \& Sandra, M., (2013): Reliability and validity of the Facial Pain Scale - Revised in assessing acute pain in critically ill patients, American Journal of critical care, 19 (1): 55-61.

11. Mohamed H., (2017): Comparison of the effectiveness of buzzy, distracting cards and balloon inflating on mitigating pain and anxiety during venipuncture in a pediatric emergency department , American Journal of Nursing Science, 6(1): 26-32

12. Humphery G., Van de, Wiel H., (2013): The occurrence of high levels of acute behavioral distress in children and adolescents undergoing routine venipuncture. Pediatrics, 4(1):15-18.

13. Karen W., (2017): A study on the effect of distraction techniques on the pain of venipuncture in children, Health and Quality of Life Outcomes Journal, 16(59): 1-9.

14. McGrath A., \& Frager M., (2017): Psychological Interventions for Needle Related Procedural Pain and Distress in Children and Adolescents. Cochrane Database of Systematic Reviews, 127(1):1-9.

15. Nilsson S., Finnström B., \& Kokinsky E., (2008): The FPS-R behavioral scale for procedural pain assessment in children aged 516 years, Paediatr Anaesth Journal, 18(8): 767774. 
16. Sahiner N., \& Bal M., (2016): Pain management and distraction in children. Journal of Child Health Care, 2(1): 1-9.

17. Terri, K., \& Susan, C., (2013): Essentials of pediatric nursing, pain management in children, chapter 14, 2nd edition, Lippincott Williams \& Wilkins, pp.553-591.

18. Urden, L., Stacy, K., \& Lough, M., (2012): Critical Care Nursing: Diagnosis and Management, 6th ed, Missouri Mosby, pp. 211225.

19. Wallace D., \& Allen K., (2015): The "Cough Trick:" A brief strategy to manage pediatric pain from immunization injections. ediatrics, 125(2): 367-373. 